\title{
Ocular morbidity among primary school children of Dhulikhel, Nepal
}

\author{
Sherpa $\mathrm{D}^{1}$, Pant $\mathrm{CR}^{2}$, Joshi $\mathrm{N}^{3}$ \\ ${ }^{1}$ Assistant Professor, Nepal Eye Hospital, Tripureshwor, Kathmandu \\ ${ }^{2}$ Professor, Department of Ophthalmolgy, Kathmandu University School of Medical \\ Sciences, Dhulikhel Hospital, Dhulikhel, Kavrepalanchowk, Nepal \\ ${ }^{3}$ Optometry, BP Koirala Lions Centre For Ophthalmic Studies, Kathmandu, Nepal
}

\begin{abstract}
Background: Knowledge of disease pattern in children can help design preventive and curative strategies.
\end{abstract}

Objective: To study the pattern of ocular morbidity among the primary school children.

Subjects and methods: All the children of randomly-selected five government primary schools of Dhulikhel were included in this study. A complete eye examination was done in all children including color vision, loupe examination, refraction and Schiotz tonometry. Funduscopy and automated perimetry were done in selected children.

Results: A total of 466 primary school children were included in the study, of which 466 children $47(10.08 \%)$ had ocular morbidity. Refractive error was the commonest type of ocular morbidity in $11(2.36 \%)$. Hypermetropia was the commonest type of refractive error $(0.84 \%)$ in contrast to myopia $(0.64 \%)$. Conjunctivitis was the second common type of ocular morbidity $(1.71 \%)$. Glaucoma suspects accounted for $1.28 \%$, xexophthalmia 1.07 $\%$, blephatitis $0.85 \%$, amblyopia $0.43 \%$, color blindness $0.43 \%$, conjunctival nevus 0.43 $\%$, glaucoma $0.43 \%$, and strabismus $0.43 \%$, while congenital abnormalities were less common.

Conclusion: Refractive error is the commonest form of ocular morbidity in primary school children.

Key words: primary school children, refractive error

\section{Introduction}

Childhood blindness refers to a group of diseases and conditions occurring in childhood or early adolescence, which, if left untreated, result in blindness or severe visual impairment that are likely to be untreatable later in life. Using the World Health Organization (WHO) classification of levels of visual impairment (WHO, 1992) it is estimated that globally almost one in 1000 children are blind, which is less than a tenth of the prevalence in adults (Foster Received on: 24.01.2011 Accepted on: 19.05.2011 Address for correspondence: Dr Dakki Sherpa, Assistant Professor, Nepal Eye Hospital, Tripureshwor, Kathmandu Tel: 00977-1-4495661, E-mail: dakki_sherpa@yahoo.com
\& Gilbert, 1997; Foster \& Gilbert, 1992). However, the 1.5 million blind children in the world account for about 75 million person years of blindness (Eckstein et al 1995) equivalent to the burden due to cataract-related blindness, which accounts for $40 \%$ of adult blindness worldwide (Smith \& Smith, 1996). Blindness has an enormous personal, social and economic cost, limiting the education and life choices of otherwise healthy people, and placing a significant weight on family, community, and social and health services. The magnitude of childhood blindness has not been studied in this purposed area. A study 'Ocular morbidity in school children' done 
in Kathmandu (Nepal et al 2003), the adjoining district of Kavre by Nepal et al (2002), revealed $11 \%$ of ocular morbidity. A program to provide basic eye screening to schoolchildren with an aim to provide services as well as gather information on ocular morbidity was carried out. This research study could contribute in the prevention of this problem through awareness programs related to eye health in schools and in the community. Also, the problems could be treated through mobile eye camps with referrals to eye hospitals. This study was carried out to determine the prevalence of ocular morbidity among primary school children of Dhulikhel.

\section{Subjects and methods}

A descriptive cross-sectional study was carried out to see ocular morbidity in primary school children of Dhulikhel Municipality of Kavre Palanchowk District of Nepal. Study area and sampling technique: The children of five government primary schools of Dhulikhel municipality were selected by stratified random sampling technique. An informed consent was obtained from the school headmasters. All the children attending the allocated primary schools of Dhulikhel were included in the study. Children who were unwilling to participate or were absent at the time of the school visit were excluded.

Data collection tool: Data were collected by interviews and clinical examinations. Data collection procedure: Appropriate arrangements were made for the screening at a given date and time. Cooperation was sought from the teachers at schools. They were trained on the spot in vision screening and detection of common ocular problems. A short talk supported by charts, posters etc, regarding eye health education was given to the children at each visit. The team carrying out the school screening consisted of an ophthalmologist, an optometrist, a senior ophthalmic assistant, an intern, a health assistant trainee and a driver.

The materials taken with the team were Snellen E charts, binocular loupes, torch lights, rulers, direct ophthalmoscopes, retinoscopes, trial sets, trail frames, Ischihara color vision charts, posters and pro formas.

The students underwent the following examination. Detailed history taking was performed and the findings recorded in pro formas. Visual acuity unaided, pinhole and with glasses from a distance of 6 metres were assessed with the help of a Snellen's E chart and a tumbling E chart. Color vision was assessed with an Ischihara color vision chart.

- Extra-ocular movements cover tests, and convergence tests were done.

- Examination of anterior segment was done with the help of binocular loupe and a torch light.

- Retinoscopy and subjective refraction were done.

- A cycloplegic refraction was done followed by subjective refraction after 3 days.

- Intraocular pressure was measured with the help of a Schiotz tonometer when glaucoma was suspected.

- Fundus evaluation with a direct ophthalmoscope. Fundus evaluation under full mydriasis was done whenever needed with instillation of $1 \%$ tropicamide eyedrop.

- Chidren with glaucoma suspect were taken to B.P.Koirala Lion Centre for Ophthalmic Studies, where visual field analysis was done by an automated perimeter.

The diagnostic criteria used in the study were as follows. Adiagnosis of myopia was made if the refractive error was more than - 0.5 dioptre. Similarly, hypermetropia was recorded if it was more than +0.75 dioptre after cycloplegic refraction. The drugused for cycloplegic refraction was tropicamide $1 \%$ used twice, one drop in each eye, at an interval of 10 minutes. Astigmatism was recorded if it was more than 0.50 dioptre. A diagnosis of amblyopia was made if the vision was $6 / 9$ or worse after a careful eye examination including funduscopy through dilated pupil and cycloplegic refraction. Strabismus was diagnosed by recording the corneal light reflex combined with the cover test. 
Vitamin Adeficiency was determined by recording conjunctival dryness and Bitot's spot with or without a history of night blindness. The history of night blindness was obtained from the students themselves, which was later confirmed by their parents on a subsequent visit. Glaucoma suspects were diagnosed based on the criteria that included a cup disc ratio of $>0.5$ with glaucomatous optic nerve head changes, a cup disc asymmetry between the fellow eyes of $>0.2$, and/or intraocular pressure (IOP) $>21 \mathrm{mmHg}$ by a Schiotz tonomer. Glaucoma was diagnosed by the presence of glaucomatous optic nerve head changes and visual field changes. Statistics: Collected data were analyzed using SPSS version 11.5.

The parameters studied were age and gender, ocular morbidity, visual acuity, and the causes of visual impairment.

\section{Results}

A total of 466 primary school children were included in this study. Of these, 47 children had ocular morbidity which accounted for $10.08 \%$. Table 1 shows the age and gender distribution of the primary school children included in the study. Out of 466 children, there were 223 males and 243 females. 129 male children $(27.68 \%)$ and 127 female children $(27.25 \%)$ were in the age group of 5 - 10 years. The mean age of the primary school children included in this study was $9.26 \pm 2.49$ years. Table 2 shows the ocular morbidity pattern of primary school children. There were 47 patients with ocular morbidity, of which $11(2.36 \%)$ were children with refractive error and, $8(1.71 \%)$ with conjunctivitis ( 1 was allergic and 7 were infective in etiology). There were $6(1.28 \%)$ children with glaucoma suspect, 5 (1.07\%) with xerophthalmia, 4 (0.85 $\%)$ children were suffering from blepharitis, 2 (0.43 $\%$ ) children had amblyopia (1 child had anisometropic amblyopia and the other child had ametropic amblyopia). There were $2(0.43 \%)$ children with color blindness, $2(0.43 \%)$ with conjunctival naevus, $2(0.43 \%)$ had glaucoma, 2 $(0.43 \%)$ had strabismus, $1(0.21 \%)$ had congenital ptosis, $1(0.21 \%)$ had pinguecula and $1(0.21 \%)$ had iris coloboma. There were $3(0.64 \%)$ children with myopia, $4(0.84 \%)$ with hypermetropia and 3 $(0.64 \%)$ had astigmatism.

There were $4(0.85 \%)$ children with visual acuity of $6 / 9-6 / 18$ and $2(0.43 \%)$ children with visual acuity of $6 / 18-6 / 60$. There were $6(1.29 \%)$ children with visual morbidity. Of these, refractive error accounted for $100 \%$ for the cause of visual morbidity. Of these, $1(0.21 \%)$ was due to simple hypermetropic astigmatism, $1(0.21 \%)$ was due to compound myopic astigmatism, $2(0.21 \%)$ were due to simple myopia, $1(0.21 \%)$ was anisometropic amblyopia and $1(0.21 \%)$ was due to ametropic amblyopia.

\section{Table 1}

\section{Age and sex distribution of the primary} school children

\begin{tabular}{|c|c|c|c|c|}
\hline $\begin{array}{c}\text { Age group } \\
\text { (in years) }\end{array}$ & Male & $\begin{array}{c}\text { Percentage } \\
\mathrm{N}=223\end{array}$ & Female & $\begin{array}{c}\text { Percentage } \\
\mathrm{N}=243\end{array}$ \\
\hline $0-5$ & 18 & 3.86 & 21 & 4.50 \\
\hline $5-10$ & 129 & 27.68 & 127 & 27.25 \\
\hline $10-15$ & 76 & 16.30 & 95 & 20.38 \\
\hline
\end{tabular}

Table 2

\section{Ocular morbidity pattern of the primary school children}

\begin{tabular}{|l|c|c|}
\hline Ocular morbidities & $\begin{array}{c}\text { Number of } \\
\text { children }\end{array}$ & $\begin{array}{c}\text { Percentage } \\
\mathrm{N}=466\end{array}$ \\
\hline Refractive error & 11 & 2.36 \\
\hline Conjunctivitis & 8 & 1.71 \\
\hline Glaucoma suspects & 6 & 1.28 \\
\hline Xerophthalmia & 5 & 1.07 \\
\hline Blepharitis & 4 & 0.85 \\
\hline Amblyopia & 2 & 0.43 \\
\hline Colour Blindness & 2 & 0.43 \\
\hline Conjuctival naevus & 2 & 0.43 \\
\hline Glaucoma & 2 & 0.43 \\
\hline Strabismus & 2 & 0.43 \\
\hline Congenital ptosis & 1 & 0.21 \\
\hline Pinguecula & 1 & 0.21 \\
\hline Iris coloboma & 1 & 0.21 \\
\hline Total & 47 & 10.05 \\
\hline
\end{tabular}




\section{Discussion}

A descriptive cross-sectional study was carried out to see ocular morbidity in primary school children of Dhulikhel Municipality of Kavre Palanchowk District of Nepal from September 2007 to November 2007. A total of 466 primary school children were included in this study. Out of 466 primary school children, 47 children had ocular morbidity which accounts for $10.08 \%$. This result is comparable with the study 'Ocular morbidity in school children' done in Kathmandu, the adjoining district of Kavre, which revealed $11 \%$ of ocular morbidity (Nepal et al 2003).

Out of the 466 children, there were $223(47.85 \%)$ males and $243(52.14 \%)$ females. 129 male children $(27.68 \%)$ and 127 female children (27.25 $\%)$ were in the age group of $5-10$ years. The mean age of the primary school children included in this study was $9.26 \pm 2.49$ years. This is comparable to a study by Nepal et al (2003), where 505 (45.90 $\%)$ were males and $595(54.09 \%)$ were females. The mean age of the study population was 9.5 years. In this study $11(2.36 \%)$ were children with refractive error, the most common cause of ocular morbidity. The Nepal Blindness Survey (Brilliant GE 1988) found refractive error, based on pinhole correction, to be $1.3 \%$. However, refractive error was not measured here. Another study conducted in eastern Nepal found refractive error in schoolchildren to be less than $3 \%$ (Pokharel GP et al 2000).

Refractive error was the commonest type of ocular morbidity ( $8.1 \%$ ) in a study by Nepal et al (2002). Studies (Jialiang Zhao et al 2000, Maul Eet al 2000, Chaturvedi $S$ 1999) in China revealed refractive error to be $12.8 \%$, Chile $15.8 \%$ and Delhi, India $7.4 \%$. On the other hand, a study (Wedner SH et al 2000) in rural Tanzania of primary school children showed a refractive error of (1\%). These large differences in the prevalence of refractive error among these studies may be because that the Nepal Blindness Survey was conducted more that 20 years ago and was a population-based survey and the study in eastern Nepal involved a different geographical location and different ethnic groups. The primary school children included in our study were from a rural area. This finding implies that difference in lifestyles (for example reading, watching $\mathrm{TV}$, or computer and visual display units), living conditions (for example nutrition) or medical care (for example unnecessary or overcorrection of refractive errors which may worsen the refractive error by inhibiting natural "emmetropisation") may be more important than racial/ethnic differences. There were $3(0.64 \%)$ children with myopia, 4 $(0.84 \%)$ with hypermetropia and $3(0.64 \%)$ had astigmatism. Hyperopia was the commonest refractive error which was comparable to a study conducted in Nigeria where hyperopia $(7.8 \%)$ was the predominant refractive error (Faderin et al 2001). Conjunctivitis (1.71\%) was the second common cause of ocular morbidity in our study. Among 8 $(1.71 \%)$ children of conjunctivitis (one had an allergic and seven had an infective etiology). A study conducted in the city of Pataila in India showed the prevalence rate of conjunctivitis to be $3.27 \%$ (Singh et al 1974).

In our study, the prevalence of glaucoma suspect was $1.28 \%$. A similar study conducted in Nigeria showed the prevalence of glaucoma suspect to be $0.8 \%$ (Abdulkabir et al 2008). Vitamin Adeficiency was found to be $1.71 \%$ in our study. This is comparable with the prevalence of Vitamin A deficiency of $1.65 \%$ in the Nepal xerophthalmia survey (Upadhyay et al 1985), of $0.76 \%$ in Nepal Blindness Survey (Brilliant (1988) and of $0.67 \%$ in the study from eastern Nepal ( Pokharel et al 2000). In our study, blepharitis accounted for 0.8 $\%$ of ocular morbidity. This is similar with the study which shows the prevalence rate of blepharitis to be $0.6 \%$ (Singh Set al 1074). Strabismus accounts for $0.43 \%$ in our study. This prevalence of strabismus is similar to the study conducted in India in which the prevalence of strabismus was $0.3 \%$ (Reddy 1987). Exotropia and exophoria were the predominant types of strabismus. Exotropia was more prevalent than esotropia in studies in Chile 
(Maul et al 2000), eastern Nepal (Pokharel et al 2000) and Hong Kong (Yu et al 2002).

There were $4(0.85 \%)$ children with visual acuity of $6 / 9-6 / 18$ and $2(0.43 \%)$ children with visual acuity of $6 / 18-6 / 60$. There were $6(1.29 \%)$ children with visual morbidity. Out of the $6(1.29$ $\%)$, refractive error was present in $4(0.8 \%)$, this being the commonest cause of visual impairment (67\%) among primary school children, the rest as a result of amblyopia (33\%). This is comparable with a refractive error study from the Mechi Zone of Nepal (Pokharel et al 1997), which showed that $2.9 \%$ children had visual morbidity of which $56 \%$ was due to refractive error (Pokharel 2000).

\section{Conclusion}

Refractive error is the main cause of visual impairment in primary school children of Dhulikhel. Amblyopia is the second important cause of visual disability. This study clearly depicts the need to launch a periodic school eye screening to prevent permanent visual disability of the school children.

Acknowledgement: I would like to thank University Grant Commission for providing fund for this study. I would like to thank the staff of Ophthalmology Department of Kathmandu University School of Medical Sciences, Dhulikhhel for their support. I would like to express my sincere gratitude to the technical staff of BP Koirala Lions Centre for Ophthalmic Studies, Tribhuvan University Teaching Hospital for their technical support during the study period.

\section{References}

Brilliant GE. (1988). The epidemiology of blindness in Nepal. Chelsea, Michigan: the Seva Foundation.

Chaturvedi S, Agrawal OP (1999). Pattern and distribution of ocular morbidity in primary school children of rural Delhi. Asia Pacific Journal of Public Health; 11 (1):30-3.
Faderin M A, Ajaiyeoba A I ( 2001). Refractive Errors in Primary school children in Nigeria Nigerian Journal of Ophthalmology; 9(1):10-14.

Jialiang Zhao, Xiangjun Pan, Ruifang Sui et al (2000). Refractive error study in children: results from Shunji District, China. Am J Ophthalmol; 129 (4):427-35.

Maul E, Barroso S, Munoz SR et al (2000). Refractive error study in children: results from $\mathrm{La}$ Florida, Chile. Am J Ophthalmol;129 (4):445-54.

Nepal BP, Koirala S, Adhikary S, Sharma AK (2003). Ocular morbidity in school childrenin Kathmandu. Br J Ophthalmol; 87(5): 531-534.

Pokharel GP. Negrel AD, Munoz SR et al (2000). Refractive error study in children: results from Mechi Zone, Nepal. Am J Ophthalmol;129(4):436-44.

Reddy SC (1987). Ocular morbidity and colour blindness among school children in Kakinada. The Antiseptic; 84 (5):611-6.

Singh S, Singh H,Joshi VS.(1974) Eye diseases among primary school children. Indian $\mathbf{J}$ Ophthalmol; 22 (1) (1):1-3.

Upadhyay MP, Gurung BP, Pillai KK, et al (1985). Xerophthalmia among Nepalese children. Am J Epidemiol; 121 (1):71-7.

Wedner SH, Ross DA, Baliva R et al ( 2000). Prevalence of eye diseases in primary school children in a rural area of Tanzania. Br J Ophthalmol; 84(11):1291-7.

World Health Organisation.(1992). International statistical classification of diseases and health related problems. 10th revision. Geneva.

Yu CBO, Fan DSP, Wong VWY et al (2002). Changing pattern of strabismus: a decade of experience in Hong Kong. Br J Ophthalmol; 86 (8):854-6.

Source of support: declared. Conflict of interest: none 